\title{
A study on the effect of nutrient intake on the body mass index of mothers of children with food allergies
}

\author{
Yasuko Fukuda, ${ }^{1}$ Shumi Yamamoto, ${ }^{1}$ Kyoko Nishida, ${ }^{2}$ Yuri Takaoka, ${ }^{3}$ Makoto Kameda ${ }^{3}$
}

\begin{abstract}
Background: No previous studies have reported the effect of the presence of children with food allergies (FAs) on the diet and body mass index (BMI) of mothers. Therefore, we conducted a dietary survey and considered nutrients that influenced BMI of mothers.

Objective: Subjects included 554 mothers -305 mothers of children with FAs (FA mothers; aged $38.4 \pm 5.1$ years, FA group) and 249 mothers of children without FAs (non-FA mothers; aged $37.7 \pm 5.5$ years, NFA group).

Methods: We extracted dietary patterns from dietary survey results and investigated the correlation between nutrient intake and BMI. We divided the FA group into two groups (one containing 181 mothers whose children were allergic to $\leq 1$ of the three major allergenic foods-eggs, milk and wheat-and another containing 124 mothers whose children were allergic to $\geq 2$ of these foods) and conducted a comparative analysis.
\end{abstract}

Results: BMI was significantly lower in the FA group than in the NFA group $\left(20.7 \mathrm{vs} .21 .4 \mathrm{~kg} / \mathrm{m}^{2}\right)$. There was a significant negative correlation between BMI and vegetable protein intake $(\beta=-0.196, \mathrm{SE}=0.05)$. Vegetable protein intake was higher in the group that was allergic to $\geq 2$ of the allergenic foods.

Conclusion: BMI of FA mothers is affected by a diet that strictly follows their FA child's allergen-free state-a diet dominated by vegetable protein. These observations suggested that the degree to which an FA mother is affected depends on the number of the three major allergenic foods to which her FA child is allergic.

Key words: food allergy, mothers, body mass index, diet, vegetable proteins

\section{From:}

${ }^{1}$ Department of Food Science and Nutrition,

School of Human Environmental Sciences,

Mukogawa Women's University, Hyogo Prefecture, Japan

${ }^{2}$ Department of Nutrition Management, Osaka Prefecture Medical

Center for Respiratory and Allergic Diseases, Osaka Prefecture, Japan

Department of Pediatrics, Osaka Prefecture Medical Center for

Respiratory and Allergic Diseases, Osaka Prefecture, Japan

\section{Introduction}

The families of food allergy (FA) children-particularly mothers-are likely to experience heightened anxiety levels. Strong recommendations have been made regarding issues such as the preparation of allergen-free meals, avoidance of the accidental ingestion of allergens, and method of providing first aid in the event of anaphylaxis, ${ }^{1-3}$ but it is not sufficiently offered to FA mothers and families.

The recommended treatment for FAs entails the removal of as few items as possible from the diet based on the proper diagnosis for causative allergens and their replacement with alternatives as necessitated by the type and quantity of items
Corresponding author:

Yasuko Fukuda

Email: yafukuda@mukogawa-u.ac.jp

removed. ${ }^{4-7}$ To maintain an allergen-free diet and avoid the accidental ingestion of allergens, dietary habits of families of FA children tend to reflect the same allergen-free diet as required for their children. However, even when the number of allergenic items removed is kept to a minimum, they feel the burden. ${ }^{8-14}$ Furthermore, the mental and emotional stress of living with FAs can take its toll and have a detrimental effect on the quality of life (QOL) of mothers. ${ }^{15,16}$ Anaphylaxis is related to the anxiety level of the mother. ${ }^{16}$ A previous study has reported a possible effect of FA on body mass Index (BMI) of mothers under psychological stress because although FA 
mothers do not have a lower energy intake than NFA mothers, they are leaner-the more allergies their child has in terms of the three major allergenic foods, the lower is their $\mathrm{BMI}$, and the more strictly they follow the allergen-free diet, the lower is their QOL. ${ }^{14}$

In general, low BMI can be caused by factors such as illness, overwork, psychological stress, an unbalanced diet, or an increase in daily activity. No studies have reported how the presence of a child with FAs affects the diet, lifestyle, and BMI of the mother. Therefore, to ascertain the dietary influence, rather than studying dietary intake alone, it is necessary to also evaluate the dietary content. In this study, we expanded the scope of our investigation to include dietary content and studied the diets of mothers with young children, analyzed their dietary patterns, and investigated the nutrients that influenced BMI of FA mothers.

\section{Methods}

Subjects included 305 mothers of FA children (FA group; aged $38.4 \pm 5.1$ years) who were treated at the Department of Pediatrics of the Osaka Prefectural Medical Center for Respiratory and Allergic Diseases (currently known as the Osaka Habikino Medical Center) between July 2013 and August 2016 and 249 mothers whose children had no FAs (NFA group; aged $37.7 \pm 5.5$ years), making a total of 554 mothers.

The exclusion criteria were mothers with some type of physical or psychological disorder, those taking prescription medications, or those with children suffering from some type of chronic condition other than allergies.

We explained the objectives of the study to mothers who were waiting for a consultation and inquired regarding their willingness to participate in the study. A questionnaire was then provided to the mothers who consented to participate. If a certain mother returned multiple questionnaires during the survey period, then only the first one was considered for the study to avoid overlapping. Furthermore, with the NFA group, the staff conducting the survey confirmed that the mother did not have an FA child and that the child had no dietary restrictions due to other diseases.

The study was a cross-sectional survey conducted using a self-administered questionnaire, including a profile and dietary survey.

\section{Profile survey}

Factors such as the age of the child; family composition; and the age, height, and weight of the mother were surveyed, and BMI was calculated by dividing weight $(\mathrm{kg})$ by height squared $\left(\mathrm{m}^{2}\right)$. An additional questionnaire was provided to the FA group to evaluate the number and types of causative food, whether a substitute food was being used, and whether any anaphylaxis had been experienced.

\section{Dietary survey}

The survey was conducted using a brief-type, self-administered diet history questionnaire (BDHQ). Energy content and nutrient intake by the food group were calculated using the nutrient density method (all parameters other than energy was calculated per 1,000 kcal), and the results were compared between the FA and NFA groups. The BDHQ is used to estimate energy content, nutrient intake, and food intake by the food groups based on the frequency of eating certain foods in a week over the most recent 1-2 months. ${ }^{17}$

\section{Dietary patterns and maternal attributes}

Dietary patterns were extracted on the basis of the intake volume per food group for the 15 food items included in the BDHQ. The principal component extraction standard was an Eigen value of $\geq 1$. Factor loading for the food groups representing the principal components was set at $\geq 0.30$.

The FA group was divided into two groups as one containing 181 mothers whose children were allergic to one or none of the three major allergenic foods (eggs, milk, or wheat) or to other foods ( $\leq 1$ group) and the other containing 124 mothers whose children were allergic to two or more of the three major allergenic foods ( $\geq 2$ group). We then compared the two groups in terms of maternal attributes and food and nutrient intake.

\section{Statistical processing}

SAS Version 9.4 (SAS Institute Inc., Cary, NC, USA) was used for statistical processing, and data are presented as mean \pm standard deviation (mean $\pm \mathrm{SD}$ ).

The Welch t-test was used to compare differences in the average values between the two independent groups. Principal component analysis was used to extract dietary pattern. Spearman rank correlation analysis was used to examine the relationship between principal components and maternal attributes. Logistic regression analysis was used to investigate the correlation between the presence of FAs and maternal attributes or the relationship between FA and foods and nutrients comprising the first principal component. Multiple regression analysis was used to inspect the correlation between BMI and maternal attributes or the foods and nutrients comprising the first principal component. Statistical significance was set at $<5 \%$.

\section{Ethical considerations}

This study was approved by the Ethical Review Board of the Osaka Prefectural Medical Center for Respiratory and Allergic Diseases (currently known as Osaka Habikino Medical Center) (Approval no. 777-2; approved on August 24, 2016) and the Research Ethics Committee of the Mukogawa Women's University and Junior College (Approval no. 16-87; approved on December 17, 2016) and was conducted in accordance with the Helsinki Declaration. The study content was explained to the subjects beforehand, and their written consent was obtained. Consent was also obtained for the use of sensitive information in this study, and personal information was pseudonymized when conducting the analysis. 


\section{Results}

\section{Profile survey}

Maternal BMI was significantly lower in the FA group $\left(20.7 \pm 2.7 \mathrm{~kg} / \mathrm{m}^{2}\right)$ than in the NFA group $\left(21.4 \pm 3.4 \mathrm{~kg} / \mathrm{m}^{2}\right)$ $(P=0.007$, Table 1$)$. No difference was noted in the proportion of people with $\mathrm{BMI}<18.5 \mathrm{~kg} / \mathrm{m}^{2}$ between the two groups (Table 1). There were no differences in terms of the age of mothers between the FA $(38.4 \pm 5.1$ years $)$ and NFA $(37.7 \pm$ 5.5 years) groups and in terms of the age of children between the FA $(7.1 \pm 3.3$ years $)$ and NFA $(7.1 \pm 3.9$ years $)$ groups.

Table 1. Patient characteristics

\begin{tabular}{|c|c|c|c|c|c|}
\hline & \multicolumn{2}{|c|}{$\begin{array}{l}\text { Non-food } \\
\text { allergy group }\end{array}$} & \multicolumn{2}{|c|}{$\begin{array}{l}\text { Food allergy } \\
\text { group }\end{array}$} & $P$-value \\
\hline Number of mothers & \multicolumn{2}{|c|}{249} & \multicolumn{2}{|c|}{305} & \\
\hline Age of mothers (year) & 37.7 & $( \pm 5.5)$ & 38.4 & $( \pm 5.1)$ & 0.102 \\
\hline $\begin{array}{l}\text { Body mass index (BMI) } \\
\left(\mathrm{kg} / \mathrm{m}^{2}\right)\end{array}$ & 21.4 & $( \pm 3.4)$ & 20.7 & $( \pm 2.7)$ & $0.007^{* *}$ \\
\hline $\begin{array}{l}\mathrm{BMI}<18.5 / 18.5 \\
\text { or }>18.5 / 18.5(\mathrm{n})\end{array}$ & \multicolumn{2}{|c|}{$37 / 212$} & \multicolumn{2}{|c|}{$60 / 245$} & 0.146 \\
\hline Age of child (year) & 7.1 & $( \pm 3.9)$ & 7.1 & $( \pm 3.3)$ & 0.918 \\
\hline Number of families & 4.3 & $( \pm 1.0)$ & 4.1 & $( \pm 1.0)$ & $0.047^{\star}$ \\
\hline
\end{tabular}

Data are expressed mean ( \pm standard deviation) Mann-Whitney U-test *, $P<0.05^{\star *}, P<0.01$

\section{Dietary survey}

\section{2-1 Nutrient intake}

Nutrient intake in the FA and NFA groups is shown in Table 2. There were no differences in terms of energy (kcal/ $\mathrm{kg})$, protein, or vegetable protein $(\mathrm{g} / 1,000 \mathrm{kcal})$ intake between the two groups.

\section{2-2 Nutrient intake by food group}

Nutrient intake by the food group is shown in Table 2 . The intake of green and yellow vegetables, seafood, and confectionery was significantly higher in the FA group than in the NFA group, whereas that of eggs and dairy products was significantly lower in the FA group than in the NFA group. No differences were observed between the two groups in terms of the intake of other food groups.
Table 2. Intake by nutrient and food groups

\begin{tabular}{lccc} 
& $\begin{array}{c}\text { Non-food } \\
\text { allergy group }\end{array}$ & $\begin{array}{c}\text { Food allergy } \\
\text { group }\end{array}$ & P-value \\
\hline $\begin{array}{l}\text { Energy intake }(\mathrm{kcal} / \mathrm{kg}) \\
\text { Protein intake }(\mathrm{g} / 1,000\end{array}$ & $30( \pm 11)$ & $32( \pm 10)$ & 0.123 \\
kcal $)$ & $37.0( \pm 5.6)$ & $37.1( \pm 6.1)$ & 0.771 \\
Fat intake $(\mathrm{g} / 1,000 \mathrm{kcal})$ & $32.0( \pm 5.7)$ & $31.3( \pm 6.2)$ & 0.186 \\
$\begin{array}{l}\text { Carbohydrate intake } \\
\text { (g/1,000 kcal) }\end{array}$ & $130.8( \pm 19.9)$ & $134.7( \pm 18.4)$ & $0.015^{*}$ \\
$\begin{array}{l}\text { Green and yellow } \\
\text { vegetables }(\mathrm{g} / 1,000 \mathrm{kcal})\end{array}$ & $67.9( \pm 40.4)$ & $75.6( \pm 44.1)$ & $0.035^{*}$ \\
$\begin{array}{l}\text { Fruits }(\mathrm{g} / 1,000 \mathrm{kcal}) \\
\text { Fishes }(\mathrm{g} / 1,000 \mathrm{kcal})\end{array}$ & $44.3( \pm 46.2)$ & $52.3( \pm 48.9)$ & 0.052 \\
$\begin{array}{l}\text { Eggs }(\mathrm{g} / 1,000 \mathrm{kcal}) \\
\text { Milk }(\mathrm{g} / 1,000 \mathrm{kcal})\end{array}$ & $22.1( \pm 12.9)$ & $13.5( \pm 11.9)$ & $<0.001^{* * *}$ \\
\begin{tabular}{l} 
Sweets $(\mathrm{g} / 1,000 \mathrm{kcal})$ \\
\hline
\end{tabular} & $18.4( \pm 15.6)$ & $22.1( \pm 16.9)$ & $0.009^{* *}$ \\
\hline
\end{tabular}

Data are expressed as mean ( \pm standard deviation) Mann-Whitney U-test * $P<0.05^{\star *}, P<0.01^{\star * *}, P<0.001$

\section{2-3 Extraction of dietary patterns}

Factor loadings for principal components and each food group are shown in Table 3. In terms of dietary patterns, six principal components with Eigen value $\geq 1$ were extracted. The first principal component had the greatest Eigen value of 2.343 (15.6\% of total variance) among all of the principal components extracted. Furthermore, on this principal component, green and yellow vegetables and other vegetables showed high factor loadings of 0.869 and 0.799 , respectively. Moreover, because pulses (0.498), fruits (0.433), potatoes (0.375), and seafood (0.336) were also extracted, dietary patterns that were suggestive of the basic form of the elimination diet were obtained. In the second through sixth principal components, because only specific food groups in the second and third principal components showed high factor loadings, we interpreted that dietary patterns that reflected the preferences of the subjects had been extracted.

Table 3. Factor loading of each food group by principal component analysis

\begin{tabular}{lcccccc}
\multicolumn{1}{c}{ Food groups } & $\mathbf{1}^{\text {st }}$ factor & $\mathbf{2}^{\text {nd }}$ factor & $\mathbf{3}^{\text {rd }}$ factor & $\mathbf{4}^{\text {th }}$ factor & $\mathbf{5}^{\text {th }}$ factor & $\mathbf{6}^{\text {th }}$ factor \\
\hline Cereals & $-0.254^{*}$ & $-0.760^{*}$ & $0.407^{*}$ & -0.164 & 0.014 & 0.093 \\
Potatoes & $0.376^{*}$ & 0.110 & 0.071 & 0.092 & -0.015 & $0.356^{*}$ \\
Sugars & -0.139 & 0.190 & 0.182 & $0.528^{*}$ & $0.360^{*}$ & 0.165 \\
Pulses & $0.498^{*}$ & 0.029 & 0.038 & $0.353^{*}$ & $-0.477^{*}$ & 0.007 \\
Green and yellow vegetables & $0.870^{*}$ & -0.018 & -0.002 & 0.017 & 0.150 & 0.029 \\
Other vegetables & $0.799^{*}$ & 0.031 & 0.073 & 0.151 & 0.141 & 0.142 \\
\hline
\end{tabular}

*: $\mid$ load $\mid>0.30$ (in module) $\mathrm{n}=554$ 
Table 3. (Continued)

\begin{tabular}{lllllll}
\multicolumn{1}{r}{ Food groups } & $\mathbf{1}^{\text {st }}$ factor & $\mathbf{2}^{\text {nd }}$ factor & $\mathbf{3}^{\text {rd }}$ factor & $4^{\text {th }}$ factor & $5^{\text {th }}$ factor & $\mathbf{6}^{\text {th }}$ factor \\
\hline Fruits & $0.434^{*}$ & -0.159 & $-0.392^{*}$ & -0.242 & $0.251^{*}$ & -0.061 \\
\hline Fishes & $0.337^{*}$ & 0.084 & 0.063 & 0.043 & -0.073 & $-0.622^{*}$ \\
\hline Meat & 0.113 & $0.667^{*}$ & $0.299^{*}$ & $-0.392^{*}$ & 0.091 & 0.106 \\
\hline Eggs & -0.067 & $0.303^{*}$ & 0.231 & 0.229 & $-0.635^{*}$ & -0.158 \\
\hline Milk & -0.248 & $0.264^{*}$ & $-0.337^{*}$ & $0.352^{*}$ & -0.074 & $0.497^{*}$ \\
\hline Oils & -0.003 & $0.595^{*}$ & $0.364^{*}$ & $-0.468^{*}$ & 0.024 & 0.097 \\
\hline Sweets & -0.003 & 0.011 & $-0.719^{*}$ & -0.146 & -0.111 & -0.062 \\
\hline Beverages & -0.202 & $0.270^{*}$ & 0.121 & $0.476^{*}$ & $0.474^{*}$ & $-0.392^{*}$ \\
\hline Seasoning spices & 0.231 & $-0.536^{*}$ & $0.421^{*}$ & 0.077 & -0.025 & 0.122 \\
\hline SS loadings & 2.343 & 1.979 & 1.465 & 1.324 & 1.123 & 1.037 \\
\hline Proportion value (\%) & 15.6 & 13.2 & 9.8 & 8.8 & 7.5 & 6.7 \\
\hline Cumulative value (\%) & 15.6 & 28.8 & 38.6 & 47.4 & 54.9 & 61.8 \\
\hline
\end{tabular}

$*: \mid$ load $\mid>0.30$ (in module) $\mathrm{n}=554$

Table 4. Correlation between first principal component and maternal attributes

\begin{tabular}{|lcc|}
\hline & $\begin{array}{c}\text { Correlation } \\
\text { coefficient }\end{array}$ & P-value \\
\hline Food allergy & 0.1110 & $0.0089^{* *}$ \\
\hline Body mass index & -0.0919 & $0.0305^{*}$ \\
\hline Age of children & -0.0218 & 0.6080 \\
\hline Age of mothers & 0.0623 & 0.1436 \\
\hline Number of families & -0.0453 & 0.2869 \\
\hline
\end{tabular}

Spearman's rank correlation ${ }^{*}, P<0.05^{* *}, P<0.01 \mathrm{n}=554$

\section{2-4 Correlation between the first principal component and maternal attributes}

The results of an examination of the correlation between the first principal component and maternal attributes are shown in Table 4. Although a significant positive correlation was observed between the first principal component and the presence of FAs $(\rho=0.111, P=0.009)$ and a significant negative correlation was observed between the first principal component and BMI $(\rho=-0.092, P=0.031)$, no correlation was observed between maternal attributes and dietary patterns for the second principal component and onwards.

\section{2-5 Correlation between the presence of FAs and maternal attributes/food groups}

The results of a logistic regression analysis of the correlation between the presence of FAs and maternal attributes/food groups comprising the first principal component are shown in Table 5. The result of logistic regression analysis using the presence of FAs as a criterion variable and BMI, maternal age, green and yellow vegetables, other vegetables, pulses, fruits, potatoes, seafood, and vegetable protein as explanatory variables revealed significant correlations with BMI $(P=0.018)$, pulses $(P=0.012)$, seafood $(P=0.014)$, and vegetable protein $(P=0.025)$.

\section{2-6 Correlation between BMI and maternal attributes/food groups}

The results of a multiple regression analysis (stepwise regression) of the correlation between BMI and maternal attributes/ food groups comprising the first principal component are shown in Table 5. The result of a multiple regression analysis using BMI as a criterion variable and the presence of FAs, the ages of FA children and mothers, green and yellow vegetables, other vegetables, pulses, fruits, potatoes, seafood, and vegetable protein as explanatory variables revealed significant negative correlations with the presence of FAs $(P=0.009)$ and vegetable protein $(P<0.001)$ and a significantly positive correlation with other vegetables $(P=0.027)$.

\section{2-7 Comparison according to three major allergenic foods}

The results of a comparison of the FA group whose children were allergic to one or none of the three major allergenic foods ( $\leq 1$ group) and the FA group whose children were allergic to two or more of the three major allergenic foods ( $\geq 2$ group) are shown in Table 6. Although the age of FA children was significantly lower in the $\geq 2$ group $(6.5 \pm 3.0$ years $)$ than in the $\leq 1$ group $(7.5 \pm 3.4$ years $)(P=0.014)$, there was no difference in terms of maternal age or BMI.

The use of substitute foods was significantly greater in the $\geq 2$ group than in the $\leq 1$ group, whereas significantly more mothers experienced anaphylaxis in the $\geq 2$ group than in the $\leq 1$ group. The first principal component score was significantly higher for the $\geq 2$ group $(0.32 \pm 1.13)$ than for the $\leq 1$ group $(-0.03 \pm 1.02)(P=0.006)$.

Protein intake was significantly greater in the $\geq 2$ group than in the $\leq 1$ group, and there was no difference in terms of animal protein intake. Vegetable protein intake was higher in the $\geq 2$ group than in the $\leq 1$ group. 
Table 5. Correlation between the presence of FAs, body mass index, and maternal attributes/food groups comprising the first principal component

\begin{tabular}{|c|c|c|c|c|c|c|c|}
\hline & OR & $95 \%$ & P-value & $\begin{array}{l}\text { Regression } \\
\text { coefficient }\end{array}$ & $\begin{array}{l}\text { Standard } \\
\text { error }\end{array}$ & $t$ value & P-value \\
\hline Body mass index & 0.933 & $0.880-0.988$ & $0.018^{*}$ & & & & \\
\hline Pulses & 0.987 & $0.977-0.997$ & $0.012^{*}$ & & & & \\
\hline Fishes & 1.010 & $1.000-1.020$ & $0.014^{*}$ & & & & \\
\hline Vegetable protein & 1.110 & $1.010-1.210$ & $0.025^{*}$ & & & & \\
\hline Food allergy & & & & -0.670 & 0.255 & -2.634 & $0.009^{\# \#}$ \\
\hline Other vegetables & & & & 0.006 & 0.003 & 2.218 & $0.027^{\#}$ \\
\hline Vegetable protein & & & & -0.196 & 0.050 & -3.919 & $<0.001^{\# \# \#}$ \\
\hline
\end{tabular}

Logistic regression analysis ${ }^{*}, P<0.05 \mathrm{n}=554$

Stepwise multiple regression analysis ${ }^{\#}, P<0.05^{\# \#}, P<0.01^{\# \#}, P<0.001 \mathrm{n}=554$

Table 6. Comparisons of nutrient intakes between group with $\leq 1$ major allergenic foods and group with $\geq 2$ major allergenic foods

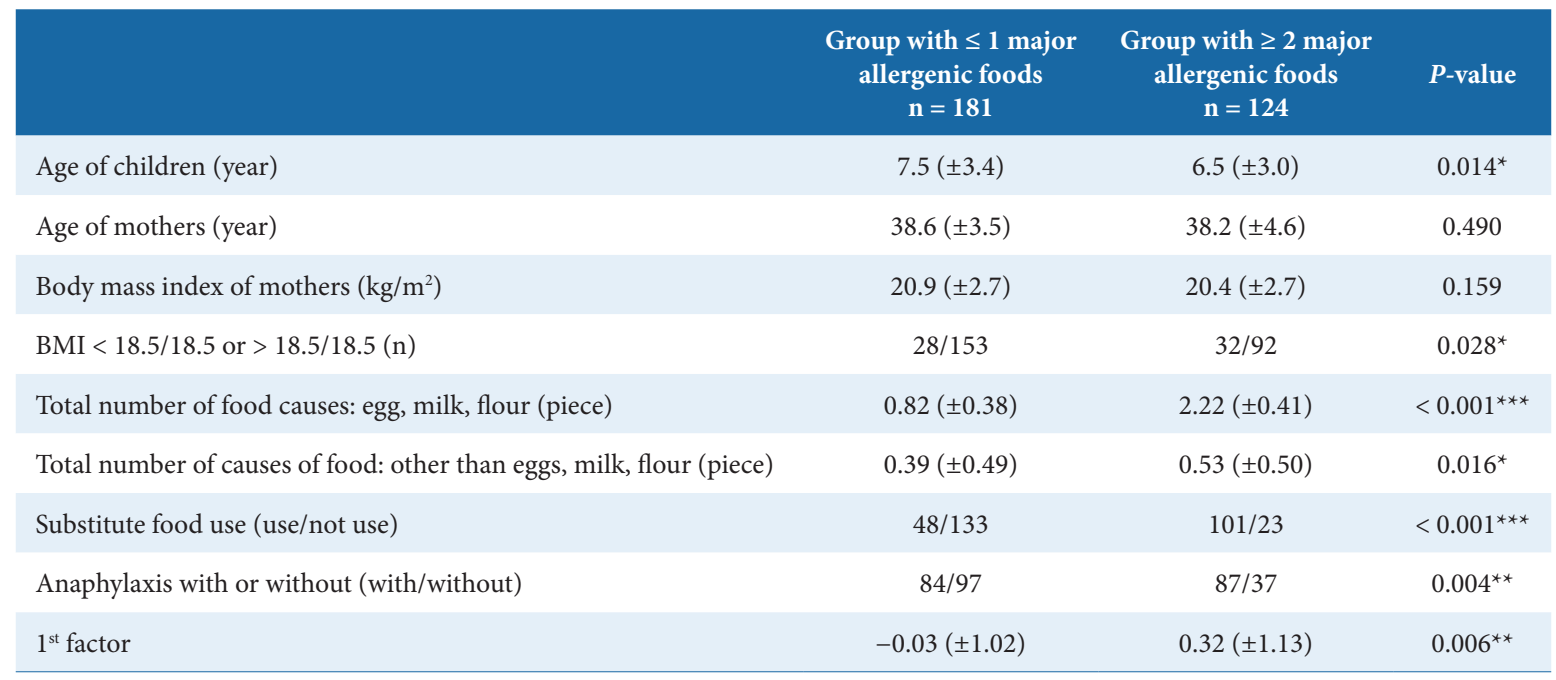

Data are expressed as mean ( \pm standard deviation) Mann-Whitney U-test ${ }^{*} ; P<0.05^{\star *}, P<0.01^{* * *}, P<0.001$

\section{Discussion}

The aim of the present study was to investigate how the presence of children with FAs affected the eating habit and BMI of the mothers by focusing on the meal content of the mothers and identifying the nutritional intake that affected BMI. Therefore, we conducted a dietary survey of mothers of children with FAs to investigate their dietary patterns.

The results revealed that the FA group had significantly lower BMI than the NFA group. Furthermore, the first principal component was diet, which was dominated by foods of plant origin, such as vegetables and pulses, demonstrating that this dietary pattern was suggestive of a basic allergen-free diet for FA children and that it was associated with FAs and BMI of FA mothers. Moreover, within the FA group, children who were allergic to two or more of the three major allergenic foods were significantly younger than those who were allergic to one or none of the allergenic foods, and there were significantly more children among them who used non-allergenic substitute foods or who had experienced anaphylaxis.
In addition, their first principal component score was higher, and they showed a tendency to consume more vegetable protein.

These result suggested a correlation between BMI of FA mothers and the quantity of food consumption including vegetable protein, such as vegetables and pulses, and that the quantity was related to the extent to which the FA child was allergic to the three major allergenic foods, the age at which the FA child began to display allergic symptoms, the use of non-allergenic substitutes, and the experience of anaphylaxis. With regard to the baseline survey, no difference was noted in the BMI of the mothers before pregnancy between the FA mothers $\left(20.0 \pm 2.1 \mathrm{~kg} / \mathrm{m}^{2} ; \mathrm{n}=266\right)$ and the NFA mothers $\left(20.4 \pm 2.9 \mathrm{~kg} / \mathrm{m}^{2} ; \mathrm{n}=201\right)$ low BMI can be attributed to the ineffective absorption of nutrients and/or to the increased energy consumption as a result of disease. ${ }^{18}$ However, subjects with such diseases were excluded from the present study. 
We then examined the lack of adequate food intake. Although no significant difference was found in terms of energy and protein intake between the FA and NFA groups, results from our prior investigation demonstrated that mothers whose children had eggs as a cause $(11.9 \pm 10.6 \mathrm{~g} / 1,000 \mathrm{kcal}$; $\mathrm{n}=229)$ had significantly lower intake of eggs $(P<0.001)$ than mothers whose children did not $(18.1 \pm 14.0 \mathrm{~g} / 1,000$ $\mathrm{kcal}, \mathrm{n}=76$ ). Furthermore, mothers whose children had milk as a cause $(72.7 \pm 57.8 \mathrm{~g} / 1,000 \mathrm{kcal} ; \mathrm{n}=135)$ had significantly lower intake of milk $(P=0.002)$ than mothers whose children did not $(95.8 \pm 69.4 \mathrm{~g} / 1,000 \mathrm{kcal} ; \mathrm{n}=170)$. We thus confirmed that low intake in food groups were associated with the cause of allergy.

This suggested that the mother's diet conforms to the allergen-free diet of the child

We also examined the meal content of FA mothers. The basic allergen-free diet-a vegetable protein-dominant dietary pattern-was extracted as a first principal component, demonstrating that the BMI of FA mothers is correlated to vegetable protein intake. A comparison of the number of the three major allergenic foods to which children were allergic revealed that greater the number of allergenic foods and stricter the allergen-free diets were followed, greater is the tendency for higher vegetable protein intake. Therefore, it is believed that vegetable protein intake affects BMI.

A research report on soy protein-a vegetable proteinand serum lipids has stated that the types of proteins synthesized during the digestion of soy protein are involved in suppressing the increases in serum cholesterol concentrations ${ }^{19}$ and affect liver enzymes responsible for the synthesis and degradation of lipids and the synthesis of triglycerides. ${ }^{20}$ Soy protein can regulate lipid metabolism by affecting the absorption of neutral fats and cholesterol. ${ }^{21}$ This shows that the types of protein in the diet may affect lipid levels and BMI.

Even in the present study, it is conceivable that soy protein intake is dominant in the dietary patterns of children consuming allergen-free diets. The association between vegetarian diets (which restrict animal protein in favor of fruit and vegetables) and body fat indicators, such as BMI, has been investigated in several large cohort studies. ${ }^{22-26}$ Individuals who ate $\geq 19$ servings of vegetables every week developed less visceral obesity. ${ }^{27}$ Furthermore, a systematic literature review of the health effects of protein intake in healthy adults suggested that vegetable protein intake is inversely correlated with blood pressure and the mortality rate from cardiovascular disease. ${ }^{28}$

These observations suggest that vegetable protein intake affects body fat. We then investigated the correlation between vegetable protein intake and BMI and indeed found a significant negative correlation. Vegetable protein intake not only affects the body fat but also has a positive influence on visceral fat, cardiovascular disease, and blood pressure. However, in a study of the relationship between the muscle mass of healthy women and their animal protein intake, it was reported that animal protein intake is an independent predictor of muscle mass index. ${ }^{29}$ To prevent the loss of muscle mass, biases toward vegetable protein consumption must not be overlooked.
Moreover, when a low BMI are accompanied by calcium and/or vitamin D deficiency, there is a greater likelihood of developing osteoporosis. ${ }^{30}$ As the risk of osteoporosis increases even more when menopause is included as a factor, it is necessary to increase bone mass and density from an early age to prevent osteoporosis. Furthermore, heavy drinking can reduce bone density, which causes osteoporosis and/or bone fractures. $^{30}$

There is the possibility that children's digestive system develops as they grow up and they become able to tolerate allergens and eat a wider variety of foods, including foods that would have previously triggered reactions. There is the need for further study on changes in the diets of FA mothers with the growth of their children. While nutritional guidance to FA children is essential, nutritional support to FA mothers is also important.

The strengths of the present study were that lower BMI and leanness were observed among FA mothers and that nutrients that influence BMI were extracted. As far as we could ascertain, this correlation between BMI and nutrient intake of FA mothers was not observed in other studies and this study appears to be the first to report these aspects in combination. The questionnaire completion rate was high, and the necessary sample size could be collected. Furthermore, because there was not much difference between the two groups (FA and NFA) in terms of the average age of mothers and because their backgrounds were similar, high-quality comparisons could be made. With the BDHQ, we could calculate intake for approximately 30 different types of nutrients and for approximately 50 different types of food, enabling us to comprehensively analyze the meal content.

The limitations of the present study are as following: there was no blood test data of the subjects (such as serum neutral fat levels), body composition measurements (such as body fat percent) were not taken, height and weight measurements were self-reported, which poses the possibility of recall bias, and the questionnaire was only administered during the summer (July and August). Accordingly, it is undeniable that there are limitations on how the results of the present study may be interpreted. In addition, weight loss may occur due to impacts from the amount of daily activity and housework related to child rearing; however, this was not investigated in the present study. We plan to investigate these aspects in the future.

\section{Conclusion}

An investigation of dietary patterns of mothers with young children indicated a first principal component suggestive of a basic allergen-free diet for FA children (mainly comprising vegetables, pulses, fruit, and potatoes). The first principal component was observed to be significantly correlated with the presence of FA and mothers' BMI. Significant correlations were also observed between the presence of FAs and vegetable protein intake and between maternal BMI and vegetable protein intake. These results indicated that BMI of FA mothers may be affected by a diet that follows their FA child's allergen-free diet (i.e., meals dominated by vegetable protein). Moreover, the degree to which an FA mother is affected may depend on the number of foods to which 
her FA child is allergic. Our findings thus helped to discover a nutritional issue that is peculiar to FA mothers. In the future, we believe that the influence on other siblings, the father, and other family members of FA children living together should be investigated.

\section{Acknowledgments}

We would like to express our gratitude to the parents who took their children for care at the Pediatrics Department of the Osaka Prefectural Medical Center for Respiratory and Allergic Diseases (currently known as the Osaka Habikino Medical Center) and who kindly consented to participate in this study. The authors declare no financial/commercial conflicts of interests.

This work was supported by JSPS KAKENHI Grant Number JP17K00950.

\section{Author Contributions}

- Yasuko Fukuda ${ }^{1}$ Draw up research plan. Matters regarding ethical research screening. Provide detailed explanation of research to subjects, Collect/analyze data. Prepare initial draft.

- Shumi Yamamoto ${ }^{1}$ Guidance/advice regarding English translation.

- Kyoko Nishida ${ }^{2}$ Matters regarding ethical research screening. Collect data.

- Yuri Takaoka ${ }^{3}$ Explain research to subjects and obtain their consent.

- Makoto Kameda ${ }^{3}$ Draw up research plan. Matters regarding ethical research screening. Explain research to subjects and obtain their consent

\section{References}

1. Hu W, Grbich C, Kemp A. Parental food allergy information needs: a qualitative study. Arch Dis Child. 2007;92:771-5.

2. Xu Y, Waserman SB, Waserman S, Connors L, Stawiarski K, Kastner M. Food allergy management from the perspective of patients or caregivers, and allergists: a qualitative study. Allergy Asthma Clin Immunol. 2010;6:30.

3. Vargas PA, Sicherer SH, Christie L, Keaveny M, Noone S, Watkins D, et al. Developing a food allergy curriculum for parents. Pediatr Allergy Immunol. 2011;22:575-82.

4. National Food Allergy Group 2014 Investigative Committee [Internet]. [place unknown]: National Food Allergy Research Group; [2014]. Food Allergy Management 2014; [cited 2018 Apr 30]. Available from: https:// www.foodallergy.jp/wp-content/themes/foodallergy/pdf/manual2014.pdf. Japanese.

5. Centre for Clinical Practice at NICE. Food Allergy in Children and Young People: Diagnosis and Assessment of Food Allergy in Children and Young People in Primary Cara and Community Settings. London: National Institute for Health and Clinical Excellence; 2011.

6. Boyce JA, Assa'ad A, Burks AW, Jones SM, Sampson HA, Wood RA, et al. Guidelines for the diagnosis and management of food allergy in the United States: summary of the NIAID-sponsored expert panel report. Nutr Res. 2011;31:61-75.

7. Muraro A, Werfel T, Hoffmann-Sommergruber K, Roberts G, Beyer K, Bindslev-Jensen C, et al. EAACI Food Allergy and Anaphylaxis Guidelines: diagnosis and management of food allergy. Allergy. 2014;69: 1008-25.

8. Aika S, Ito M, Yamamoto Y. Food allergy response capabilities of mothers and related factors. Nurs Health Sci. 2017;19:340-50.
9. Allen CW, Bidarkar MS, vanNunen SA, Campbell DE. Factors impacting parental burden in food-allergic children. J Paediatr Child Health. 2015;51:696-8.

10. Annunziato RA, Shemesh E, Weiss CC, Izzo GN, D’Urso C, Sicherer SH. An assessment of the mental health care needs and utilization by families of children with a food allergy. J Health Psychol. 2013;18:1456-64.

11. Chow C, Pincus DB, Comer JS. Pediatric food allergies and psychosocial functioning: examining the potential moderating roles of maternal distress and overprotection. J Pediatr Psychol. 2015;40:1065-74.

12. Knibb RC, Semper H. Impact of suspected food allergy on emotional distress and family life of parents prior to allergy diagnosis. Pediatr Allerg Immunol. 2013;24:798-803.

13. Broome-Stone SB. The psychosocial impact of life-threatening childhood food allergies. Pediatr Nurs. 2012;38:327-30.

14. Fukuda Y, Takagi A, Yamamoto S, Nakajima R, Nishida K, Takaoka Y, et al. [Investigation on nutrient intakes and QOL of mothers with children having food allergies]. Jpn Soc Pediatr Clin Allergy. 2015;13:19-27. Japanese.

15. Lau GY, Patel N, Umasunthar T, Gore C, Warner JO, Hanna H, et al. Anxiety and stress in mothers of food-allergic children. Pediatr Allergy Immunol. 2014;25:236-42.

16. Knibb RC, Barnes C, Stalker C. Parental self-efficacy in managing food allergy and mental health predicts food allergy-related quality of life. Pediatr Allergy Immunol. 2016;27:459-64.

17. Kobayashi S, Honda S, Murakami K, Sasaki S, Okubo H, Hirota N, et al. Both comprehensive and brief-type self-administered diet history questionnaires have reasonable ranking ability for nutrient intakes compared with 16-day dietary records in Japanese adults. J Epidemiol. 2012;22:151-9.

18. Blackburn GL, Bistrian BR, Maini BS, Schlamm HT, Smith MF. Nutritional and metabolic assessment of the hospitalized patient. J Parenter Enteral Nutr.1977;1:11-21.

19. Sugano M, Yamada Y, Yoshida K. [Hypocholesterolemic effect of soy protein isolate in rats (viii): effect of protein digests on serum cholesterol]. Soy Protein Res. 1987;8:104-7. Japanese.

20. Iritani N, Suga A, Fukuda H, Katsurada A, Tanaka T. Effect of dietary casein and soybean protein on triglyceride turnover in rat liver. J Nutr Sci Vitaminol. 1988;34:309-15.

21. Torres N1, Torre-Villalvazo I, Tovar AR. Regulation of lipid metabolism by soy protein and its implication in diseases mediated by lipid disorders. J Nutr Biochem. 2006;17:365-73.

22. Fraser GE, Dysinger PW, Best C, Chan R. Ischemic heart disease risk factors in middle-aged Seventh-day Adventist men and their neighbors. Am J Epidemiol. 1987;126:638-46.

23. Orlich MJ, Singh PN, Sabaté J, Jaceldo-Siegl K, Fan J, Knutsen S, et al. Vegetarian dietary patterns and mortality in Adventist Health Study 2. JAMA Intern Med. 2013;173:1230-8.

24. Chang-Claude J, Hermann S, Eilber U, Steindorf K. Lifestyle determinants and mortality in German vegetarians and health-conscious persons: results of a 21-year follow-up. Cancer Epidemiol Biomarkers Prev. 2005; 14:963-8.

25. Thorogood M, Carter R, Benfield L, McPherson K, Mann JI. Plasma lipids and lipoprotein cholesterol concentrations in people with different diets in Britain. Brit Med J. 1987;295:351-3.

26. Key TJ, Fraser GE, Thorogood M, Appleby PN, Beral V, Reeves G, et al. Mortality in vegetarians and non-vegetarians: a collaborative analysis of 8300 deaths among 76,000 men and women in five prospective studies. Public Health Nutr. 1998;1:33-41.

27. Kahn HS, Tatham LM, Rodriguez C, Calle EE, Thun MJ, Heath CW Jr. Stable behaviors associated with adults' 10-year change in body mass index and likelihood of gain at the waist. Am J Public Health. 1997;87: 747-54.

28. Pedersen AN, Kondrup J, Børsheim E. Health effects of protein intake in healthy adults: a systematic literature review. Food Nutr Res. 2013;30-57.

29. Aubertin-Leheudre M, Adlercreutz H. Relationship between animal protein intake and muscle mass index in healthy women. Br J Nutr. 2009; 102:1803-10.

30. Orimo H, Nakamura T, Hosoi T. Japanese 2011 guideline for prevention and treatment of osteoporosis-executive summary. Arch Osteoporosis. 2012;7:3-20. 